\title{
The Association Between Covariates, with Emphasis on Maternal Body Mass Index, and Duration of Exclusive and Total Breastfeeding
}

Ing-Marie Claesson, Maria Myrgard, Malin Wallberg and Marie Blomberg

The self-archived postprint version of this journal article is available at Linköping University Institutional Repository (DiVA):

http:/ / urn.kb.se/ resolve?urn=urn:nbn:se:liu:diva-167738

N.B.: When citing this work, cite the original publication.

Claesson, I., Myrgard, M., Wallberg, M., Blomberg, M., (2020), The Association Between Covariates, with Emphasis on Maternal Body Mass Index, and Duration of Exclusive and Total Breastfeeding, Breastfeeding medicine. https:// doi.org/ 10.1089/ bfm.2019.0138

Original publication available at:

https:/ / doi.org/ 10.1089/ bfm.2019.0138

Copyright: Mary Ann Liebert

http:// www.liebertpub.com/ 
The association between covariates, with emphasis on maternal body mass index, and duration of exclusive and total breastfeeding; a cohort study in south-eastern Sweden

Running title: Duration of breastfeeding

Ing-Marie Claesson, RNM, $\mathrm{PhD}^{1}$, Maria Myrgård, $\mathrm{MD}^{2}$, Malin Wallberg, RN, MNSc${ }^{2}$, Marie Blomberg, $\mathrm{MD}, \mathrm{PhD}^{1}$

${ }^{1}$ Department of Obstetrics and Gynaecology, and Department of Clinical and Experimental Medicine, Linköping University, Linköping, Sweden

E-mail: Ing-Marie.Claesson@liu.se Marie.Blomberg@regionostergotland.se

${ }^{2}$ Child Health Unit, and Department of Clinical and Experimental Medicine, Linköping University, Linköping, Sweden

E-mail: Maria.Myrgard@regionostergotland.se Malin.Wallberg@regionostergotland.se

Word count for: Abstract: 219. Manuscript main text: 2959

Number of tables: 4

Number of figures: 3

$\underline{\text { Key words: }}$ age, body mass index, breastfeeding, covariates, parity

Funding Sources: This research did not receive any specific grant from funding agencies in the public, commercial, or not-for-profit sectors.

\section{Correspondence:}

Ing-Marie Claesson

Department of Obstetrics and Gynaecology

Department of Clinical and Experimental Medicine

Linköping University

SE - 58183 Linköping, Sweden

Tel.+46101032923Ｅ-mail: Ing-Marie.Claesson@liu.se 


\section{Abstract}

Objective: The aim of this study was to evaluate the association between possible covariates, with emphasis on maternal body mass index (BMI), on exclusive breastfeeding and on total breastfeeding during the first postnatal year.

Design: A longitudinal study encompassing 723 women who were followed during the first postnatal year

Methods: Data concerning pregnancy, delivery, neonatal period and breastfeeding were extracted from respective medical records. Sociodemographic data on the participants were self-reported. The Cox Proportional Hazard Model was used for investigating the effects of different covariates.

Results: Compared with women with BMI $<25.0$, obese women ran a higher risk of ceasing exclusive breastfeeding prematurely $($ Hazard ratio $(\mathrm{HR})=1.38, \mathrm{p}=0.009)$. Multiparous women had a lower risk of ceasing the exclusive breastfeeding prematurely, than primiparous women $(\mathrm{HR}=0.78, \mathrm{p}=0.009)$. Concerning exclusive breastfeeding as well as total breastfeeding, the risk of prematurely ceasing the breastfeeding decreased with increasing age $(p=0.028$ and $\mathrm{p}=<0.001$, respectively).

Median duration of exclusive breastfeeding was shorter among obese women compared with women with BMI <30.0 (3.0 vs 6.0 months). Corresponding figures for total breastfeeding were 4.0 vs 8.0 months. Concerning parity and exclusive breastfeeding there was no difference in median duration between primiparous women and multiparous women (4.0 months), whereas multiparous women had a longer median duration of total breastfeeding, than primiparous women (8.0 vs 7.0 months) 
Conclusion: The risk of ceasing exclusive breastfeeding prematurely is high among obese women. This result indicates the need for targeted supportive interventions, individualized according to BMI. With increasing age, the risk of ceasing breastfeeding prematurely decreases, and compared with primiparous women, multiparous women run a lower risk of ceasing exclusive breastfeeding prematurely.

\section{Introduction}

Breastfeeding is considered as a natural choice for most women. It provides the child with adequate nutrients for growth and development and several studies have reported short- and long-term health benefits for the child as well as for the woman (1-3). Moreover, breastfeeding provides economic and environmental advantages to society (4). According to the recommendation of the World Health Organization (WHO), which has been accepted by many countries, including Sweden, the child should be exclusively breastfed during the first six months of life. Continued breastfeeding, along with appropriate complementary food is proposed during the first two years of life, or for as long as the parents and child wish (5). Despite the recommendation from the WHO and the knowledge about the benefits of breastfeeding, the goal of continued breastfeeding is not often reached by many countries, nor in Sweden $(6,7)$. Among children six months of age, only $14 \%$ were exclusively breastfed, whereas just over 50\% were partially breastfed in Sweden in the year 2016 (7).

Maternal obesity has been reported to have a negative impact on breastfeeding. In comparison with normal weight women, obese women have a lower intention to breastfeed $(8,9)$, decreased odds of initiating breastfeeding (10-12), shorter breastfeeding duration (13) and increased risk of premature cessation of breastfeeding $(10,14)$. In a limited number of studies 
the association between body mass index (BMI), gestational weight gain and breastfeeding outcome has been the focus $(12,15,16)$. The results diverge as two of the studies showed no difference in duration of breastfeeding in relation to BMI and gestational weight gain $(12,15)$, whereas a systematic review and meta-analysis (16), found that excessive gestational weight gain was a risk factor for premature cessation of any breastfeeding, among overweight women as well as among obese women. In a few studies, social factors and breastfeeding have been investigated and the results show that the duration of breastfeeding varies depending on socioeconomic status, social factors and healthy habits $(13,17)$

The aim of this study cohort study was to evaluate the association between possible covariates, with emphasis on maternal BMI, on exclusive breastfeeding and on total breastfeeding during the first postnatal year.

\section{Materials and Methods}

\section{The study context and recruitment of participants}

All data concerning women and children are registered in standardized antenatal, delivery, neonatal, and child health service records. Women with uncomplicated pregnancies are recommended to have eight to nine visits to a midwife and if necessary, additional appointments with an obstetrician. The regular program during the child's first year of life consists of visits at 1-2 weeks of age, once a month from one to six months of age and then at eight, 10 and 12 months of age. All data in connection to the controls are registered in standardized Swedish antenatal, delivery, neonatal, and child health service records.

Nurses at 41 Child Welfare Centers (CWC) in south-east Sweden were asked to individually recruit consecutively 10 breastfeeding women during the first postnatal year (i.e. a total of 1080 women). Recruitment was performed between October 2015 and December 2016, and a 
total of 723 (66.9\%) women were included in the study (Fig.1). Women who did not understand Swedish or who were breastfeeding twins were excluded. Most of the participants were recruited during their first six months of breastfeeding. Written informed consent was obtained from all the women, who also gave permission to the main author (IMC) to obtain relevant information from the pregnancy record (weight in early pregnancy ( $<15$ weeks) and in pregnancy at week 37 or later, height, possible pregnancy complications), from the delivery record (possible delivery complications), from the neonatal record (gestational length, birth weight, the health status of the infant at birth, possible care at a neonatal intensive care unit) and from the child health service record (extent of breastfeeding from two weeks until 12 months of age, possible care at pediatric hospitals). The data on marital status, occupation, educational level, tobacco habits and health status were self-reported by the women on inclusion in the study.

\section{Outcome measures}

The extent of breastfeeding (exclusively breastfed since birth, fully breastfed in the last seven days, predominantly breastfed in the last seven days, partially breastfed in the last seven days or not breastfed in the last seven days) was documented in the record at the CWCs at each visit and further extracted for the purpose of this study. In this study, exclusive breastfeeding is defined to mean that the infant has solely been given breastmilk since birth, whereas total breastfeeding means that the infant has had periods of exclusive breastfeeding as well as periods of partial breastfeeding. The duration of exclusive breastfeeding and total breastfeeding were analyzed in the present study.

\section{Study variables}

Based on measured weight and height data in early pregnancy ( $<15$ weeks), BMI was

calculated and the WHO classifications of underweight $\left(<18.5 \mathrm{~kg} / \mathrm{m}^{2}\right)$, normal weight (18.5 to 
$<25.0 \mathrm{~kg} / \mathrm{m}^{2}$ ), overweight (25.0 to $29.9 \mathrm{~kg} / \mathrm{m}^{2}$ ), and obesity ( $\geq 30.0 \mathrm{~kg} / \mathrm{m}^{2}$ ) were adopted (18).

In the group of underweight women there were few participants; therefore, they were combined with the group of normal weight women.

Besides BMI the following covariates were used in the analyses: age (the mean age at the inclusion in the study), parity (primiparous women or multiparous women), marital status (married/cohabiting with a partner or other family situation), education level $(\leq />12$ years of education), occupation (gainfully employed/parental leave/student or not gainfully employed), tobacco use (absent or present), incidences of complications during pregnancy and delivery (absent or present), gestational weight gain (defined as the difference between the first registered weight information in early pregnancy and registered weight information in pregnancy week 37 or later. The gestational weight gain in relation to BMI in early pregnancy was classified according to recommended weight gain ranges provided by the Institute of Medicine (19) and in this study was categorized as inadequate, adequate or excessive.

The study was approved by the regional ethical review board in Linköping, Sweden (Dnr.2015/45-31).

\section{Statistical analyses}

All analyses were performed using SPSS 26.0 (IBM, Armonk, NY). Statistical significance was defined as (two-sided) $\mathrm{p} \leq 0.05$. The Cox Proportional Hazard Model was used for investigating the effects of above-mentioned covariates on exclusive and total breastfeeding. Women who dropped out during the study period or who were still breastfeeding at the end of the study were defined as censored. Univariable analyses with exclusive or total breastfeeding as dependent variables, and covariates as independent variables were performed to assess the hazard ratio for cession of breastfeeding prematurely. In the multivariable analyses with exclusive or total breastfeeding as dependent variables, and covariates with significant values 
in the univariable analyses as independent variables were performed to assess the hazard ratio for cession of breastfeeding prematurely.

The relationship between different BMI classes as well as the parity and the duration of exclusive breastfeeding were shown by using the Cox adjusted survival function.

\section{Results}

Initially, we performed interaction tests to assess whether the analysis should be stratified based on parity or based on gestational weight gain. The model with BMI and parity as the main factors together with their interaction effect, and the model with BMI and gestational weight gain as the main factors together with their interaction effect showed no statistically significant interactions. Therefore, we refrained from stratifications.

A total of 773 women gave written informed consent to participate in the study. A total of 17 women were excluded because there was incomplete information on them in the medical records. Furthermore, seven women were excluded as breastfeeding was not recommended due to illness, medication or medical treatment concerning themselves or their children.

Additionally, a total of 26 women were excluded as they did not breastfeed for unknown reasons. Finally, a total of 723 women participated in the study (Fig. 1). Characteristics of the participants are displayed in Table 1 . To assess possible selection bias, we investigated sociodemographic differences between women who participated in the study and women who for unknown reasons did not breastfeed and did not participate in the study for that reason (Table S1). Women who did participate in the study were younger, had a lower education level and more often not gainfully employed, compared with the study women.

The effects of covariates on the exclusive and total breastfeeding duration were investigated in univariable and multivariable regression analyses (Table 2). After adjusting for parity and age, obese women ran a higher risk of ceasing exclusive breastfeeding prematurely, compared with 
women with BMI < 25.0 (Hazard ratio $(\mathrm{HR})=1.38$, p=0.009). Furthermore, after controlling for BMI classes and age, multiparous women had a lower risk of ceasing exclusive breastfeeding prematurely than primiparous women $(\mathrm{HR}=0.78, \mathrm{p}=0.009)$ (Table 2). Based on the results of the multivariable analysis in Table 2, Figures 2 and 3 show the adjusted survival analyses of the effects of BMI and parity on the duration of exclusive breastfeeding.

Concerning the duration of exclusive as well as total breastfeeding, the multivariate analyses show that the risk of prematurely ceasing the breastfeeding decreased with increasing age ( $\mathrm{p}=0.028$ and $\mathrm{p}=<0.001$, respectively) (Table 2).

Duration of exclusive and total breastfeeding according to BMI classes and parity are shown in Table 3. Women with BMI <30 had a longer median duration of exclusive and total breastfeeding, than obese women. Concerning parity and exclusive breastfeeding, the median duration was the same in the groups of primiparous women and multiparous women, whereas primiparous women had a shorter duration of total breastfeeding, compared with multiparous women.

\section{Discussion}

In this longitudinal cohort study, we evaluated the association between possible covariates on the duration of exclusive and total breastfeeding during the first postnatal year. This period was chosen since a slightly increased prevalence of breastfeeding at nine and twelve months postnatally has been reported in Sweden during the last decade (7). We found that in comparison with women with $\mathrm{BMI}<25$, that obese women breastfed exclusively for a shorter period and had an almost $40 \%$ higher risk of ceasing breastfeeding prematurely, whereas multiparous women had just over a $20 \%$ lower risk of ceasing exclusive breastfeeding prematurely than primiparous women. Furthermore, our results indicate that the age of the 
women affects both the duration of exclusive and total breastfeeding. The risk of ceasing the breastfeeding prematurely decreased with increasing age.

Our results are both in line and in contrast with previous published studies. In an earlier study we found that five months postnatally there were more obese women who had ceased to breastfeed than underweight and normal weight women (20). A Brazilian study (21) found that obese women exclusively or totally breastfed for a shorter period than normal weight women, whereas another Brazilian study (15) reported no differences in duration of breastfeeding according to pre-pregnancy BMI. Furthermore, an American study (22) suggested that women with $\mathrm{BMI} \geq 25.0$ were less likely to breastfeed exclusively at six weeks and at six months, compared with normal weight women. Neither the study by Tao et al. (12) nor the study by Bartok et al. (23) showed an association between maternal BMI in different classes and breastfeeding outcomes after adjustment for relevant covariates. A Spanish study found that the rate of cessation of predominant breastfeeding among obese women was higher than for other women in the cohort (17). Similar results are reported in a Swedish study (24). Primiparous women had a higher risk of terminating exclusive breastfeeding within two months postpartum, compared with multiparous women, and the univariable analysis indicated that women with BMI $\geq 25.0$ had an increased risk of ceasing breastfeeding less than two months postnatally (24). In our study, the median period of exclusive breastfeeding was three months or more, irrespective of BMI class, and concerning parity the median period of exclusive breastfeeding was equal among primiparous women and multiparous women. In a systematic review and meta-analysis encompassing 17 studies, preferentially from Western countries, the authors observed a positive association between prepregnancy excess maternal weight and cessation of exclusive breastfeeding (25).

We found that with increasing age the risk of prematurely ceasing the breastfeeding decreased. This was in line with the results in the Spanish study which showed that cessation of 
predominant breastfeeding was higher in young women, compared with women in older age groups (17). On the other hand, our results differ from the Norwegian study which reported that higher maternal age was negatively associated with exclusive breastfeeding four months postpartum (13). Furthermore, Björset et al. (13) found that higher parity led to a higher likelihood of exclusive breastfeeding four and five months postpartum. This result agrees with our findings. Multiparous women had a lower risk of ceasing exclusive breastfeeding prematurely, compared with primiparous women.

The somewhat disappointing results concerning obese women in the present study are confirmed by findings in quantitative and qualitative studies. In a previous prospective study we investigated the estimated extent and duration of the forthcoming breastfeeding and found that more multiparous women with overweight and obesity judged that the forthcoming breastfeeding would be partial, compared to multiparous women with BMI <25 (20). A metasynthesis (26) showed that the obese breastfeeding women experienced ordinary difficulties to a greater degree. Medical interventions during childbirth might lead to complications and therefore possible separation from their infants, which negatively impacted breastfeeding. Furthermore, the difficulties might lead to doubt about their ability to breastfeed (26). The obese women's breastfeeding challenges are described in another study (27). They had to handle the technique of breastfeeding in a different way to normal weight women. For example, they had to adopt a particular body position so the infant could take an optimal grip on the nipple. Another challenge was the exposure of the body when breastfeeding in public. In these situations it was tempting to use formula instead of breastfeeding (27). Both studies concluded that obese women requested breastfeeding support throughout the breastfeeding period. Staff at antenatal care clinics, maternity wards and at the CWC should therefore strive to design and develop optimal breastfeeding information and breastfeeding care, in particular for obese women. 
Breastfeeding plays an important role concerning future health aspects of both the women and infants. It is well documented that breastfeeding benefits the health of the women as it can prevent breast cancer, improve birth spacing and might reduce the risk of diabetes and ovarian cancer (1). Infants who are breastfed for a longer period have been reported to have lower risk of infectious deceases, and a growing body of evidence suggests that breastfeeding might protect against overweight and obesity later in life $(1,28-31)$. Therefore, the need to encourage breastfeeding cannot be emphasized enough.

The decision on whether or not to breastfeed and the outcome of breastfeeding can be crucial for future breastfeeding choice. Da Vanzo et al.(32) suggest in their study that women often repeat the feeding method they used with their first infant with later children. Women who breastfed their first infant are likely to breastfeed a later infant, and those who did not breastfeed the firstborn, are unlikely to breastfeed a child born later. However, if the breastfeeding experience was of short duration or was perceived to be unsuccessful or unsatisfactory, the women are less likely to breastfeed a child born later (32). These results indicate the importance of providing careful support for obese primiparous women during pregnancy as well as postnatally. Rollins et al. (4) discuss the need for interventions to increase the global breastfeeding prevalence, and conclude that when relevant interventions within different areas are achieved adequately, breastfeeding practices are responsive and can improve rapidly. Concerning the area of health care services, several interventions are included in the concept of the Baby Friendly Hospital Initiative (33). Individual counseling, group education, support from specially trained health staff, immediate breastfeeding support at delivery, and breastfeeding management have been shown to increase the prevalence of exclusive or any breastfeeding up to six months postnatally (4). It is possible that supportive interventions designed for obese pregnant and postnatal women may increase the prevalence of exclusive or total breastfeeding. The antenatal breastfeeding information and education should be tailored to 
prepare the obese woman and her partner for the forthcoming task, and furthermore, the continuum of care, from antenatal care to the child health service, should offer a supportive atmosphere to protect and promote breastfeeding.

This study has both strengths and limitations. All data concerning primary outcome were extracted from medical records. Only sociodemographic data were self-reported. This is, as far as we know, one of the few studies to evaluate the association between several possible covariates on breastfeeding duration during the first postnatal year. However, there are certain limitations. We had no information concerning the health status of the women and the infant at the time of data collection. It is therefore possible that there were reasons for ceasing breastfeeding associated with diseases of the mother or the infant. When interpreting the results, one ought to keep in mind the differences between the study women and women who for unknown reasons did not breastfeed and did not participate in the study for that reason. Additionally, we had no information about race or ethnicity. It is possible that breastfeeding traditions might differ between ethnic groups. All data in the medical records were registered by the staff at the antenatal care clinics, hospitals and CWC. Despite the existence of guidelines on how to document optimally, it is possible that differences within the staff group concerning medical registration occurred (information bias). However, these putative errors are unlikely related to exposure covariates or outcomes.

\section{Conclusion}

Compared with women with BMI $<25.0$, the duration of exclusive breastfeeding was shortened among obese women, and they had a higher risk of ceasing the exclusive breastfeeding period prematurely. Multiparous women ran a lower risk of ceasing the exclusive breastfeeding period prematurely than primiparous women. Regarding both exclusive and total breastfeeding, the risk of prematurely ceasing the breastfeeding decreased with increasing age. 


\section{Acknowledgment}

We thank Lars Valter for statistical advice.

\section{References}

1. Victora CG, Bahl R, Barros AJ, Franca GV, Horton S, Krasevec J, et al. Breastfeeding in the 21st century: epidemiology, mechanisms, and lifelong effect. Lancet. 2016;387(10017):475-90.

2. Skrypnik D, Bogdanski P, Zawiejska A, Wender-Ozegowska E. Role of gestational weight gain, gestational diabetes, breastfeeding, and hypertension in mother-to-child obesity transmission. Polish archives of internal medicine. 2019.

3. Lee JW, Lee M, Lee J, Kim YJ, Ha E, Kim HS. The Protective Effect of Exclusive

Breastfeeding on Overweight/Obesity in Children with High Birth Weight. Journal of Korean medical science. 2019;34(10):e85.

4. Rollins NC, Bhandari N, Hajeebhoy N, Horton S, Lutter CK, Martines JC, et al. Why invest, and what it will take to improve breastfeeding practices? Lancet. 2016;387(10017):491-504.

$5 . \quad$ World Health Organization Available at https://www.who.int/nutrition/topics/exclusive breastfeeding/en/ Accessed December 2019 [

6. World Health Organization Available at https://www.who.int/nutrition/databases/infantfeeding/en/ Accessed December 2019 [

7. The National Board of Health and Welfare Available at https://www.socialstyrelsen.se/globalassets/sharepoint-dokument/artikelkatalog/statistik/2019-96379.pdf Accessed 19 December 2019 [

8. Turcksin R, Bel S, Galjaard S, Devlieger R. Maternal obesity and breastfeeding intention, initiation, intensity and duration: a systematic review. Matern Child Nutr. 2014;10(2):166-83.

9. Lyons S, Currie S, Peters S, Lavender T, Smith DM. The association between psychological factors and breastfeeding behaviour in women with a body mass index (BMI) $>/=30 \mathrm{~kg}$ m(-2) : a systematic review. Obes Rev. 2018;19(7):947-59.

10. Campbell T, Shackleton N. Pre-pregnancy body mass index and breastfeeding initiation, early cessation and longevity: evidence from the first wave of the UK Millennium Cohort Study. J Epidemiol Community Health. 2018;72(12):1124-31.

11. Preusting I, Brumley J, Odibo L, Spatz DL, Louis JM. Obesity as a Predictor of Delayed Lactogenesis II. J Hum Lact. 2017;33(4):684-91.

12. Tao XY, Huang K, Yan SQ, Zuo AZ, Tao RW, Cao H, et al. Pre-pregnancy BMI, gestational weight gain and breast-feeding: a cohort study in China. Public Health Nutr. 2017;20(6):1001-8.

13. Bjorset VK, Helle C, Hillesund ER, Overby NC. Socio-economic status and maternal BMI are associated with duration of breast-feeding of Norwegian infants. Public Health Nutr. 2018;21(8):1465-73.

14. Newby RM, Davies PS. Antenatal breastfeeding intention, confidence and comfort in obese and non-obese primiparous Australian women: associations with breastfeeding duration. Eur J Clin Nutr. 2016;70(8):935-40.

15. Castillo H, Santos IS, Matijasevich A. Maternal pre-pregnancy BMI, gestational weight gain and breastfeeding. Eur J Clin Nutr. 2016;70(4):431-6.

16. Huang $Y$, Ouyang YQ, Redding SR. Maternal Prepregnancy Body Mass Index, Gestational Weight Gain, and Cessation of Breastfeeding: A Systematic Review and Meta-Analysis. Breastfeed Med. 2019;14(6):366-74. 
17.

Villar M, Santa-Marina L, Murcia M, Amiano P, Gimeno S, Ballester F, et al. Social Factors Associated with Non-initiation and Cessation of Predominant Breastfeeding in a Mother-Child Cohort in Spain. Matern Child Health J. 2018;22(5):725-34.

18. WHO. Body mass index - BMI [Available from: Available at http://www.euro.who.int/en/health-topics/disease-prevention/nutrition/a-healthy-lifestyle/bodymass-index-bmi Accessed February 2019.

19. Rasmussen KM, Yaktine AL, Institute of Medicine . Committee to Reexamine IOMPWG. Weight gain during pregnancy : reexamining the guidelines. Washington, DC: National Academies Press; 2009.

20. Claesson IM, Myrgard M, Wallberg M, Blomberg M. Pregnant women's intention to breastfeed; their estimated extent and duration of the forthcoming breastfeeding in relation to the actual breastfeeding in the first year postpartum-A Swedish cohort study. Midwifery. 2019;76:102-9. 21. Sotero AM, Ferreira HDS, Assuncao ML, de Lira PIC. Pre-gestational excessive weight and duration of breast-feeding. Public Health Nutr. 2018;21(2):309-16.

22. Marshall NE, Lau B, Purnell JQ, Thornburg KL. Impact of maternal obesity and breastfeeding intention on lactation intensity and duration. Matern Child Nutr. 2018:e12732.

23. Bartok CJ, Schaefer EW, Beiler JS, Paul IM. Role of body mass index and gestational weight gain in breastfeeding outcomes. Breastfeed Med. 2012;7(6):448-56.

24. Cato K, Sylven SM, Lindback J, Skalkidou A, Rubertsson C. Risk factors for exclusive breastfeeding lasting less than two months-Identifying women in need of targeted breastfeeding support. PLoS One. 2017;12(6):e0179402.

25. Flores TR, Mielke GI, Wendt A, Nunes BP, Bertoldi AD. Prepregnancy weight excess and cessation of exclusive breastfeeding: a systematic review and meta-analysis. Eur J Clin Nutr. 2018;72(4):480-8.

26. Lyons $S$, Currie $S$, Peters $S$, Lavender T, Smith DM. The perceptions and experiences of women with a BMI >/=30kg/m(2) who breastfeed: A meta-synthesis. Matern Child Nutr. 2019:e12813. 27. Claesson IM, Larsson L, Steen L, Alehagen S. "You just need to leave the room when you breastfeed" Breastfeeding experiences among obese women in Sweden - A qualitative study. BMC Pregnancy Childbirth. 2018;18(1):39.

28. Pattison KL, Kraschnewski JL, Lehman E, Savage JS, Downs DS, Leonard KS, et al. Breastfeeding initiation and duration and child health outcomes in the first baby study. Prev Med. 2019;118:1-6.

29. Wallby T, Lagerberg D, Magnusson M. Relationship Between Breastfeeding and Early Childhood Obesity: Results of a Prospective Longitudinal Study from Birth to 4 Years. Breastfeed Med. 2017;12:48-53.

30. Wang L, Collins C, Ratliff M, Xie B, Wang Y. Breastfeeding Reduces Childhood Obesity Risks. Childhood obesity. 2017;13(3):197-204.

31. Tambalis KD, Mourtakos S, Panagiotakos DB, Sidossis LS. Association of Exclusive Breastfeeding with Risk of Obesity in Childhood and Early Adulthood. Breastfeed Med. 2018.

32. Da Vanzo J, Starbird E, Leibowitz A. Do women's breastfeeding experiences with their first-borns affect whether they breastfeed their subsequent children? Social biology. 1990;37(34):223-32.

33. WHO. Protecting, promoting, and supporting breastfeeding in facilities providing maternity and newborn services: the revised Baby-friendly Hospital Initiative 20182018 [Available from: http://www.who.int/nutrition/bfhi/en/ Accessed April 2019. 
Table 1. Characteristics of the participants

\begin{tabular}{|c|c|c|}
\hline & $\mathbf{n}$ & $\%$ \\
\hline Age (mean, SD) & 723 & $\begin{array}{c}30.3 \\
(4.81)\end{array}$ \\
\hline \multicolumn{3}{|l|}{ Body mass index } \\
\hline$<25.0$ & 427 & 59.1 \\
\hline $25.0-29.9$ & 188 & 26.0 \\
\hline$\geq 30.0$ & 108 & 14.9 \\
\hline \multicolumn{3}{|l|}{ Parity } \\
\hline Primiparous & 315 & 43.6 \\
\hline Multiparous & 408 & 56.4 \\
\hline \multicolumn{3}{|l|}{ Marital status } \\
\hline Married /cohabiting with a partner & 698 & 96.5 \\
\hline Other family situation & 25 & 3.5 \\
\hline \multicolumn{3}{|l|}{ Education level, year } \\
\hline$\leq 12$ & 343 & 48.1 \\
\hline$>12$ & 370 & 51.9 \\
\hline \multicolumn{3}{|l|}{ Occupation } \\
\hline Gainfully employed / parental leave / student & 634 & 87.7 \\
\hline Not gainfully employed & 89 & 12.3 \\
\hline \multicolumn{3}{|l|}{ Tobacco user } \\
\hline No & 692 & 95.7 \\
\hline Yes & 31 & 4.3 \\
\hline \multicolumn{3}{|l|}{ Health status (self-reported) } \\
\hline "I am healthy" & 707 & 97.8 \\
\hline "I am not healthy" & 16 & 2.2 \\
\hline \multicolumn{3}{|l|}{ Incidence of pregnancy complications } \\
\hline No & 639 & 89.4 \\
\hline Yes & 76 & 10.6 \\
\hline \multicolumn{3}{|l|}{ Incidence of delivery complications } \\
\hline No & 613 & 85.7 \\
\hline Yes & 102 & 14.3 \\
\hline \multicolumn{3}{|l|}{ Gestational weight gain* } \\
\hline Inadequate & 115 & 17.4 \\
\hline Adequate & 303 & 45.8 \\
\hline Excessive & 244 & 36.8 \\
\hline Gestational age (weeks, mean, SD) & 722 & $\begin{array}{c}39.7 \\
(1.38)\end{array}$ \\
\hline Birth weight of the infant (kg, mean, SD) & 720 & $\begin{array}{c}3.6 \\
(0.48) \\
\end{array}$ \\
\hline
\end{tabular}

* I.e. the difference between registered weight at pregnancy week $\geq 37$ and registered weight at the recruitment $(<15$ gestational weeks) 
Table 2. Cox Proportional Hazard Model for the effects of covariates on the exclusive and total breastfeeding ${ }^{\mathrm{a}}$ duration

\begin{tabular}{|c|c|c|c|c|c|c|c|c|c|c|c|c|}
\hline & \multicolumn{6}{|c|}{ Exclusive breastfeeding } & \multicolumn{6}{|c|}{ Total breastfeeding } \\
\hline & \multicolumn{3}{|c|}{ Model 1 ${ }^{\mathrm{b}}$} & \multicolumn{3}{|c|}{ Model $2^{\mathrm{C}}$} & \multicolumn{3}{|c|}{ 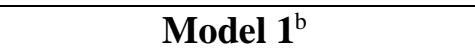 } & \multicolumn{3}{|c|}{ Model $2^{c}$} \\
\hline & $\mathrm{HR}^{\mathrm{d}}$ & $\mathrm{CI}^{\mathrm{e}}$ & $p$ & $\mathrm{HR}^{\mathrm{d}}$ & $\mathrm{CI}^{\mathrm{e}}$ & $p$ & $\mathrm{HR}^{\mathrm{d}}$ & $\mathrm{CI}^{\mathrm{e}}$ & $p$ & $\mathrm{HR}^{\mathrm{d}}$ & $\mathrm{CI}^{\mathrm{e}}$ & $p$ \\
\hline Body mass index & & & $0.045^{f}$ & & & $0.033^{\mathrm{f}}$ & & & $0.186^{\mathrm{f}}$ & & & $0.122^{f}$ \\
\hline$<25.0$ & Ref. & & & Ref. & & & Ref. & & & & & \\
\hline $25.0-29.9$ & 1.06 & $0.86-1.30$ & 0.611 & 1.09 & $0.89-1.34$ & 0.426 & 0.96 & $0.79-1.18$ & 0.726 & & & 0.941 \\
\hline$\geq 30$ & 1.36 & $1.07-1.74$ & 0.013 & 1.38 & $1.08-1.77$ & 0.009 & 1.23 & $0.96-1.57$ & 0.097 & & & 0.050 \\
\hline \multicolumn{13}{|l|}{ Parity } \\
\hline Primiparous women & Ref. & & & Ref. & & & Ref. & & & Ref. & & \\
\hline Multiparous women & 0.73 & $0.62-0.87$ & $<0.001$ & 0.78 & $0.65-0.94$ & 0.009 & 0.77 & $0.65-0.91$ & 0.003 & 0.87 & $0.72-1.05$ & 0.124 \\
\hline Age (one year increase) & 0.97 & $0.95-0.99$ & 0.001 & 0.98 & $0.96-0.99$ & 0.028 & 0.95 & $0.94-0.97$ & $<0.001$ & 0.96 & $0.94-0.98$ & $<0.001$ \\
\hline \multicolumn{13}{|l|}{ Education level $^{\circ}$, year } \\
\hline$>12$ & Ref. & & & & & & Ref. & & & Ref. & & \\
\hline$\leq 12$ & 1.16 & $0.98-1.38$ & 0.085 & & & & 1.25 & $1.05-1.49$ & 0.011 & 1.13 & $0.95-1.36$ & 0.215 \\
\hline \multicolumn{13}{|l|}{ Marital status } \\
\hline $\begin{array}{r}\text { Married / cohabiting with a } \\
\text { partner }\end{array}$ & Ref. & & & & & & Ref. & & & & & \\
\hline Other family situation & 1.06 & $0.63-1.77$ & 0.831 & & & & 0.86 & $0.52-1.44$ & 0.578 & & & \\
\hline \multicolumn{13}{|l|}{ Occupation } \\
\hline $\begin{array}{r}\text { Gainfully employed / parental } \\
\text { leave / student }\end{array}$ & Ref. & & & & & & Ref. & & & & & \\
\hline Not gainfully employed & 1.0 & $0.76-1.31$ & 0.974 & & & & 0.84 & $0.64-1.10$ & 0.205 & & & \\
\hline \multicolumn{13}{|l|}{ Tobacco user } \\
\hline No & Ref. & & & & & & Ref. & & & & & \\
\hline Yes & 1.30 & $0.85-2.00$ & 0.299 & & & & 1.21 & $0.79-1.86$ & 0.382 & & & \\
\hline
\end{tabular}




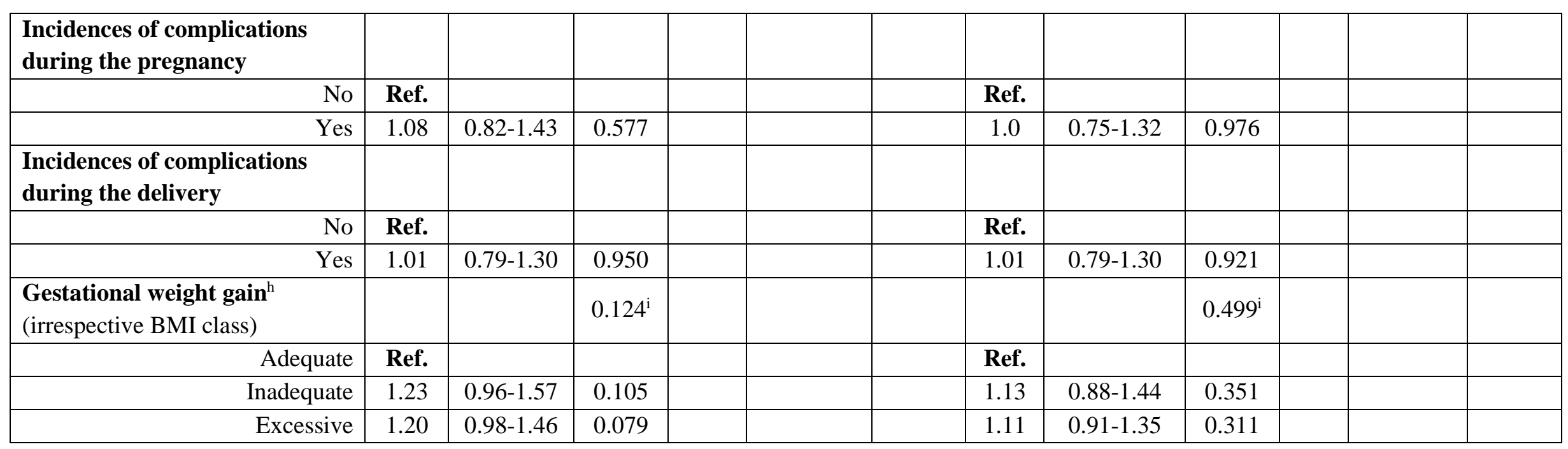

${ }^{a}$ i.e. exclusive and partial breastfeeding

${ }^{\mathrm{b}}$ Univariable analysis

c Multivariable analysis (including significant values in the univariable analysis)

${ }^{\mathrm{d}}$ Hazard ratio,

e Confidence interval (95 \%)

${ }^{\mathrm{f}}$ Overall p-value for all BMI classes (i.e. BMI <25.0, 25.0-29.9, $\geq 30.0$ )

${ }^{\mathrm{g}}$ Information on education level is missing in 10 women. Therefore, they are not included in the analysis.

${ }^{\mathrm{h}}$ Gestational weight gain according to recommendations of Institute of Medicine

${ }^{\mathrm{i}}$ Overall p-value for all gestational weight gain levels (i.e. inadequate, adequate, excessive) 
Table 3. Duration of exclusive and total breastfeeding according to body mass index (BMI) and parity

\begin{tabular}{r|c|c|c|c|c|c}
\hline & \multicolumn{3}{|c|}{$\begin{array}{c}\text { Exclusive breastfeeding } \\
\text { (months) }\end{array}$} & \multicolumn{3}{c}{$\begin{array}{c}\text { Total breastfeeding } \\
\text { (months) }\end{array}$} \\
\hline & \multicolumn{3}{|c|}{ Quartile } & \multicolumn{3}{c}{ Quartile } \\
\hline BMI classes & 1 & 2 & 3 & 1 & 2 & 3 \\
\hline $25.0-29.9$ & 1.0 & 4.0 & 4.8 & 4.0 & 8.0 & 10.0 \\
\hline$\geq 30.0$ & 1.0 & 3.0 & 4.0 & 3.0 & 6.0 & 10.0 \\
\hline Parity & & & & & & \\
\hline Primiparous women & 1.0 & 4.0 & 4.0 & 5.0 & 7.0 & 10.0 \\
\hline Multiparous women & 2.0 & 4.0 & 5.0 & 5.0 & 8.0 & 10.0 \\
& & & & & & \\
\hline
\end{tabular}




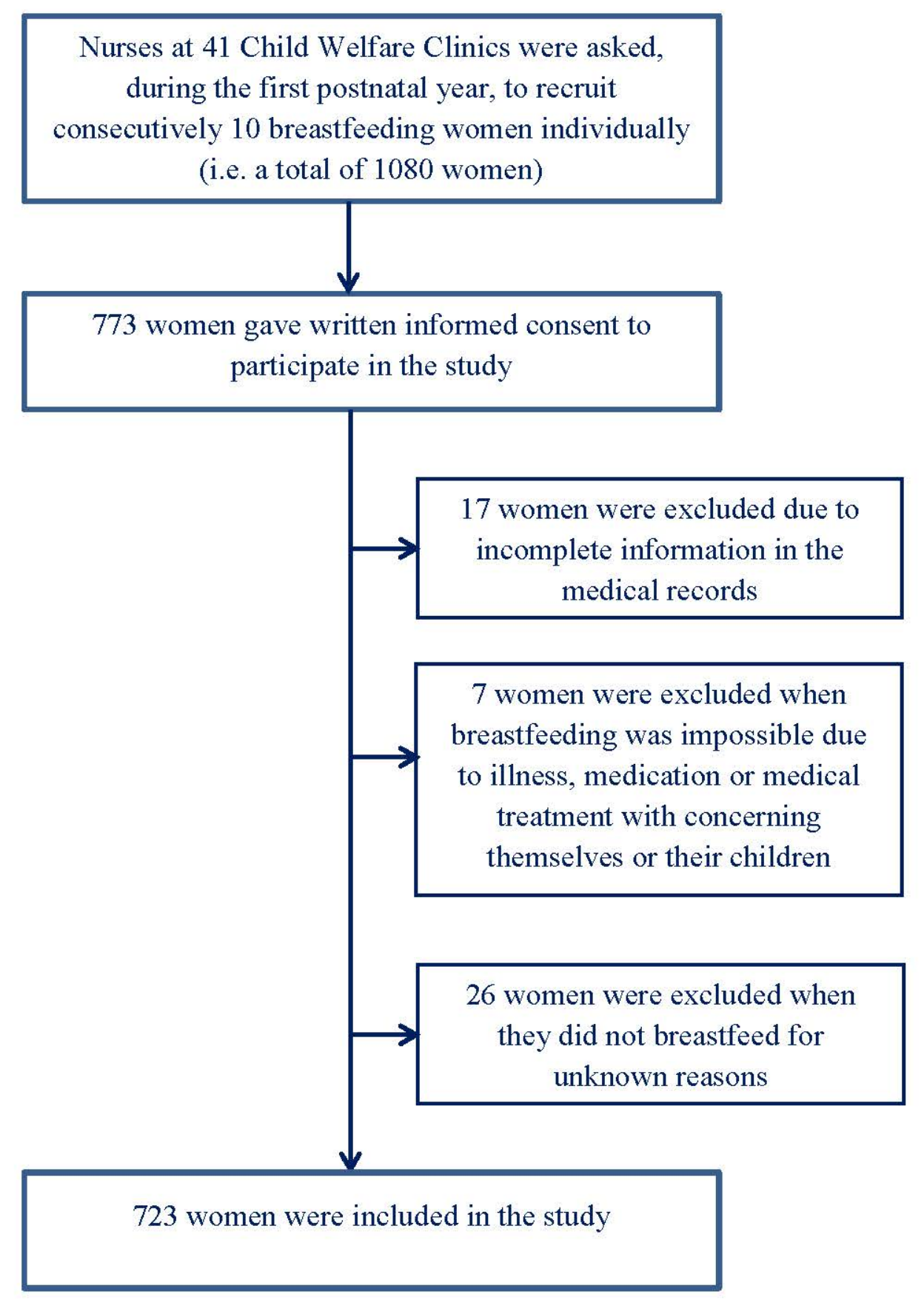

Figure 1. Description of the population in the study 


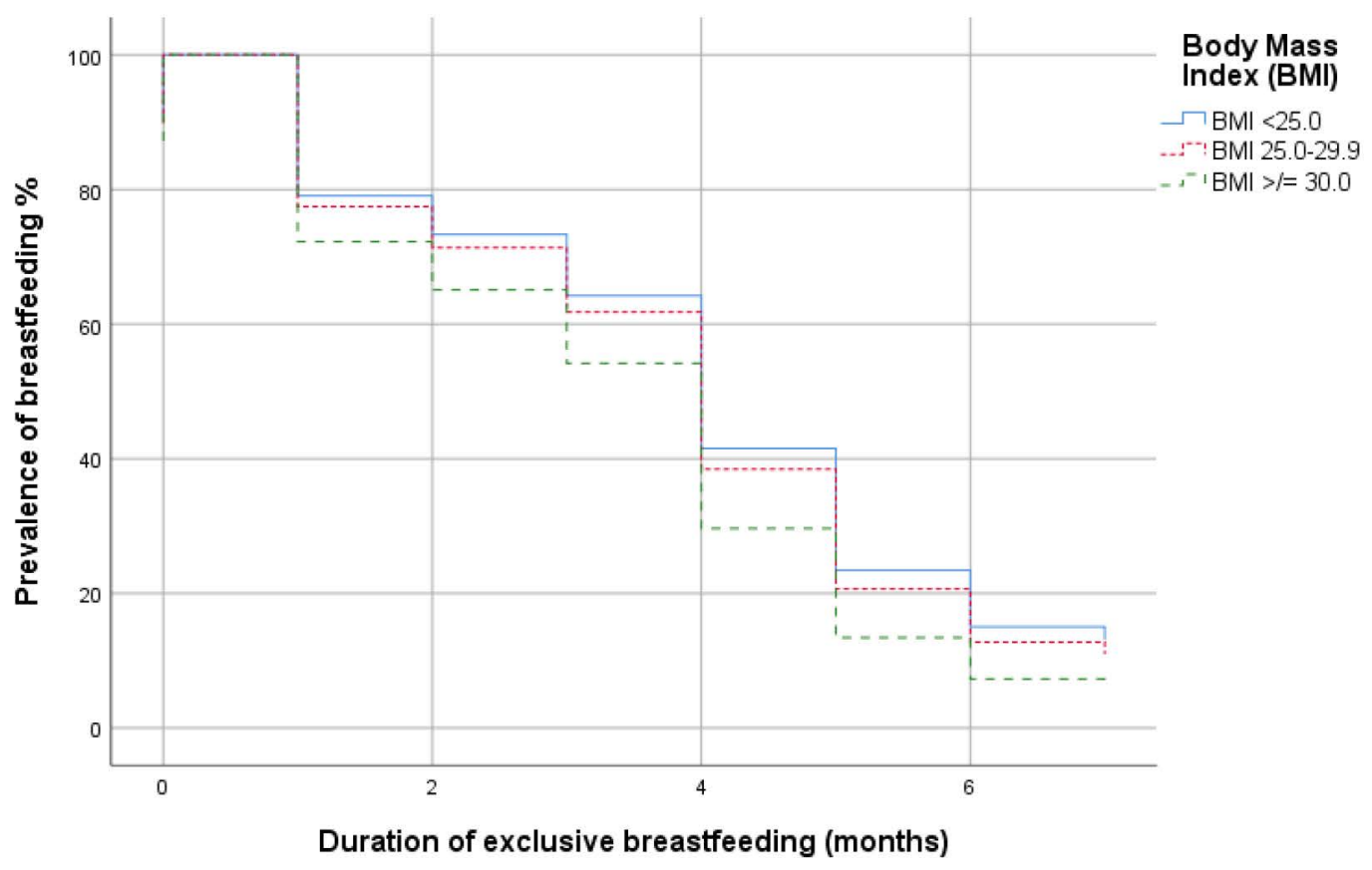

Figure 2. Cox survival function for adjusted analysis of the effects of body mass index on the duration of exclusive breastfeeding. Assessed 12 months postpartum and adjusted for parity and maternal age. 


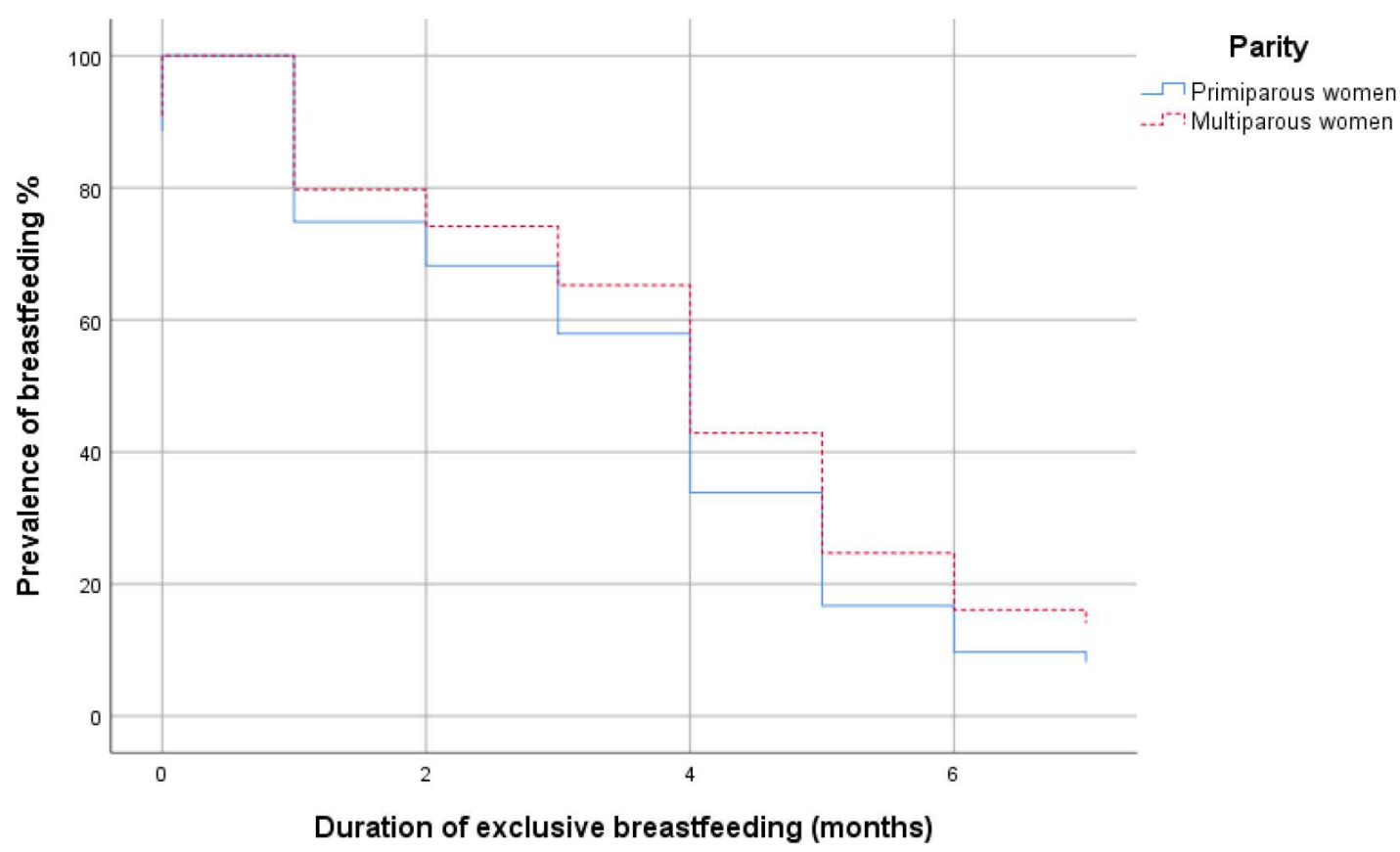

Figure 3. Cox survival function for adjusted analysis of the effects of parity on the duration of exclusive breastfeeding. Assessed 12 months postpartum and adjusted for body mass index and maternal age 
Table S1. Socio-demographic characteristics of participants in the study (i.e. women who breastfed) and non-participants in the study (i.e. women who did not breastfeed for unknown reason)

\begin{tabular}{|c|c|c|c|c|c|}
\hline & \multicolumn{2}{|c|}{$\begin{array}{l}\text { Participants in the } \\
\text { study }\end{array}$} & \multicolumn{2}{|c|}{$\begin{array}{l}\text { Non-participants in } \\
\text { the study }\end{array}$} & \multirow[b]{2}{*}{$p$} \\
\hline & $\mathrm{n}=723$ & $\%$ & $\mathbf{n}=\mathbf{2 6}$ & $\%$ & \\
\hline Age (mean, SD) & 723 & $\begin{array}{c}30.3 \\
(4.81)\end{array}$ & 26 & $\begin{array}{c}28.2 \\
(3.90)\end{array}$ & $0.011^{\mathrm{a}}$ \\
\hline Body mass index & & & & & $0.539^{c}$ \\
\hline$<25.0$ & 427 & 59.1 & 13 & 50.0 & \\
\hline $25.0-29.9$ & 188 & 26.0 & 9 & 34.6 & \\
\hline$\geq 30.0$ & 108 & 14.9 & 4 & 15.4 & \\
\hline Parity & & & & & $0.365^{b}$ \\
\hline Primiparous & 315 & 43.6 & 9 & 34.6 & \\
\hline Multiparous & 408 & 56.4 & 17 & 65.4 & \\
\hline Marital status & & & & & $0.607^{\mathrm{c}}$ \\
\hline Married /cohabiting with a partner & 698 & 96.5 & 25 & 96.2 & \\
\hline Other family situation & 25 & 3.5 & 1 & 3.8 & \\
\hline Education level, year & & & & & $0.004^{\mathrm{b}}$ \\
\hline$\leq 12$ & 343 & 48.1 & 20 & 76.9 & \\
\hline$>12$ & 370 & 51.9 & 6 & 23.1 & \\
\hline Occupation & & & & & $0.004^{\mathrm{c}}$ \\
\hline $\begin{array}{r}\text { Gainfully employed / parental leave / } \\
\text { student }\end{array}$ & 634 & 87.7 & 17 & 65.4 & \\
\hline Not gainfully employed & 89 & 12.3 & 9 & 34.6 & \\
\hline Tobacco user & & & & & $0.109^{c}$ \\
\hline No & 692 & 95.7 & 23 & 88.5 & \\
\hline Yes & 31 & 4.3 & 3 & 11.5 & \\
\hline
\end{tabular}

a Student's T-test

${ }^{\mathrm{b}}$ Pearson Chi-Square Test

${ }^{\mathrm{c}}$ Fischer’s Exact test 